\title{
PROTOCOLO PARA A AVALIAÇÃO E TRATAMENTO EM FERIDAS UTILIZANDO O LASER DE BAIXA INTENSIDADE: UMA PROPOSTA
}

\section{PROTOCOL FOR EVALUATION AND TREATMENT OF WOUNDS USING LOW LEVEL LASER THERAPY: A PROPOSAL}

\author{
Ana Lúcia Gargione Galvão de Sant'Anna ${ }^{1}$ \\ Vania Maria de Araújo Giaretta ${ }^{1}$ \\ Maria Belén Salazar Posso ${ }^{2}$
}

RESUMO: Propõe-se a elaboração de um protocolo de intervenção de enfermagem em feridas, utilizando-se Laser de Baixa Intensidade (LBI), para subsidiar profissionais de saúde no cuidado delas. Os LBI utilizados como coadjuvantes no tratamento de feridas auxiliam a restauração tecidual, melhoram a regeneração e a cicatrização dos tecidos, atuam na inflamação e no edema, aliviando a dor. Utilizou-se metodologia descritivo-exploratória com abordagem quantitativa, cuja proposta foi submetida à apreciação de 18 juízes: 06 enfermeiros, 06 físicos, 06 médicos, todos especializados no assunto, que responderam voluntariamente, observadas todas as normas éticas, questões abertas e fechadas, sobre cada item do protocolo. Os resultados da análise pelos 18 juízes evidenciaram a necessidade, a abrangência, a sistematização da avaliação e aplicação efetiva da ferida e do registro dos dados. Dois juízes sugeriram alterar somente a sequência de algumas questões e dois opinaram adicionar a relação existente entre a energia total ministrada pelo laser e as áreas totais de tratamento e a distância entre os pontos de aplicação. Os resultados obtidos permitem inferir que a proposta é importante e necessária para a terapêutica com LBI em feridas e subsidiar a sistematização dessa terapêutica pelos enfermeiros e demais profissionais de saúde capacitados para esse fim.

Palavras-chave: terapia a laser; cicatrização de feridas; avaliação; protocolo.

ABSTRACT: This work studied a protocol for evaluation and treatment of wounds with Low Level Laser Therapy (LLLT) to help health professionals treat wounds. LLLT is used as a support for wound treatment to help tissue restoration, improve tissue regeneration, and increase healing. In addition, it acts on the swelling and edema and relieves pain. A descriptive-exploratory and quantitative methodology was used. The protocol was submitted for validation to 18 judges: 6 nurses, 6 physicists, 6 physicians, who were all specialists in the matter. They voluntarily answered a questionnaire with open and closed questions and analyzed each item of the protocol. The results of the analysis from the 18 judges included important data for an effective evaluation of the wound, standardization of the evaluation and application of effects on the wound, and offered data to document it. Two judges suggested changing only the sequence of some questions and two physicists advised to add the relation existing between the total energy ministered by the laser and the total treatment areas along with the distance between the application points. The obtained results permitted us to infer that the protocol is important and necessary for therapy with LLLT on wounds, to detect possible deficiencies, and to propose corrective measures.

Keywords: laser therapy; wound healing; evaluation; protocol.

\footnotetext{
${ }^{1}$ Enfermeira. Mestre em Engenharia Biomédica. Docente da UNIVAP. E-mails: analucia@univap.br; giaretta@univap.br.

${ }^{2}$ Enfermeira. Doutora em Enfermagem. Docente da UNIVAP. E-mail: mbelen@terra.com.br.
} 


\section{INTRODUÇÃO}

A partir de experiências vivenciadas como docentes de enfermagem e fundamentadas pelos conhecimentos adquiridos no Curso de Mestrado em Engenharia Biomédica, da Universidade do Vale do Paraíba - UNIVAP, sentimos o estímulo de buscar, na literatura Nacional e Internacional, fundamentos para a elaboração e validação de protocolo para a terapêutica de feridas com 0 intuito de favorecer e instrumentalizar, de forma sistematizada, as intervenções de enfermagem e dos demais profissionais, para avaliação, cuidado/tratamento, evolução, registro e documentação dos dados do portador de ferida.

Esse intuito fortaleceu-se quando do acompanhamento e supervisão de alunos de enfermagem, tanto em estágios curriculares, como nas práticas supervisionadas em hospitais, Unidades Básicas de Saúde e, mais particularmente, no Centro de Práticas Supervisionadas da UNIVAP. Verificaram-se os problemas e as dificuldades enfrentadas pelos enfermeiros e outros profissionais de saúde para a avaliação e tratamento da ferida.

Esta observação coincide com o estudo de Morais; Oliveira; Soares (2008) desenvolvido com enfermeiros de instituições hospitalares da rede pública de João Pessoa - PB, em 2005, que, ao investigarem os aspectos considerados pelos enfermeiros ao avaliarem feridas, os recursos materiais por eles empregados para a avaliação, a utilização de protocolos e as dificuldades para a realização, concluíram que, entre outros, "a falta de material conduz a uma avaliação superficial" e "a ausência de protocolo dificulta a avaliação". Também relataram a ausência de uma comissão interdisciplinar de prevenção e tratamento das lesões cutâneas (MEIRELES et al., 2007). Isto reafirmou a oportunidade de se elaborar um protocolo de avaliação e intervenção de enfermagem em feridas, especialmente, utilizando-se o laser de baixa intensidade como terapêutica coadjuvante.

Acredita-se que uma proposta, neste caso, de protocolo para intervenção, mesmo fundamentada teoricamente, deva sofrer uma apreciação, por especialistas no tema antes de ser validada clinicamente para ser usada com segurança em locais onde se discutem e se desenvolvem atividades de assistência de enfermagem, de fisioterapia, de terapia ocupacional de modo integrado e interdisciplinar aos indivíduos.

Este estudo refere-se à elaboração de um protocolo de avaliação e tratamento de feridas com Laser de Baixa Intensidade (LBI), proporcionando subsídios aos profissionais de enfermagem e da saúde para avaliarem as feridas sob seus cuidados. Necessário se faz que, inicialmente, se retome algumas considerações gerais sobre a pele, feridas e LBI.

A pele é considerada o maior órgão do corpo humano, representando cerca de $15 \%$ do peso corporal total. Tem como funções básicas a proteção imunológica, síntese de vitamina $\mathrm{D}$ pela ação dos raios ultravioletas, termorregulação, percepção de toque, pressão, vibração, variações de temperatura e estética. É formada por três camadas diferentes: epiderme, derme e hipoderme, e embora "esta não seja considerada por muitos autores como parte integrante da pele, é estudada dentro do Sistema 
Tegumentar, assim como seus anexos (KANITAKIS, 2002; IRION, 2005; AZULAY; AZULAY, 2006; DAVENPORT, 2007; SAMPAIO; RIVITTI, 2007).

A camada mais superficial da pele é a epiderme, onde se situa a camada basal, constituída de células basais e onde se localizam os melanócitos. Essa camada é um epitélio estratificado pavimentoso queratinizado, formado por grupos celulares diferenciados, são eles: germinativo, granuloso e córneo, e apresenta espessuras diferentes conforme a região do corpo (SAMPAIO; RIVITTI, 2007).

A derme é um tecido conjuntivo que sustenta e nutre a epiderme e se localiza abaixo dela conectando-se aos cones epiteliais epidérmicos pela sua porção externa, sendo composta por fibras colágenas, fibras elásticas e fibras reticulares, ricas em muco polissacarídeo, substância essencial na composição das mesmas e possuindo uma espessura que varia de 1 a $4 \mathrm{~mm}$. A derme abriga, ainda, os músculos lisos eretores do pelo $\mathrm{e}$, mais profundamente, no limite dérmicohipodérmico localizam-se os vasos sanguíneos e linfáticos e, também, os nervos e os órgãos sensoriais inerentes a eles. São vários os tipos de sensores ali presentes, como o Corpúsculo de VaterPacini, de Meissner, de Krause, de Ruffini, de Mercke (IRION, 2005; AZULAY; AZULAY, 2006).

Já a hipoderme ou tela subcutânea, possui uma espessura variável e é formada por tecido conjuntivo frouxo ou adiposo, cujas células repletas de gordura formam lóbulos subdivididos por traves conjuntivo-vasculares. Conecta-se à derme e à fáscia muscular por meio da camada superior da hipoderme, originando a junção dermohipodérmica (SAMPAIO; RIVITTI, 2007). Ainda, esses autores consideram ser a hipoderme essencial para o sistema tegumentar, pois funciona como isolamento térmico e protege o organismo contra traumas externos e, ainda como depósito nutritivo (IRION, 2005; SAMPAIO; RIVITTI, 2007).

Quando a pele sofre uma solução de continuidade, isto é, ruptura de sua integridade, essa área é denominada ferida (DAVENPORT, 2007). A ferida recebe várias definições da comunidade científica, podendo, por exemplo, ser definida como qualquer lesão no tecido epitelial, mucosas ou órgãos com prejuízo de suas funções básicas, resultante de um agente químico, físico ou microbiano. Toda lesão que afete o paciente deve ser avaliada pelos profissionais de saúde para assistência e tratamentos adequados (AZULAY; AZULAY, 2006; MEIRELES, 2007; MORAIS; OLIVEIRA; SOARES, 2008).

As feridas devem ser avaliadas quanto à etiologia, localização, tamanho, tipo, estágio, grau de contaminação, características do leito, borda, exsudato, odor e condições da pele ao redor. Também é necessária a avaliação física do paciente e de outros fatores que influenciam a escolha do protocolo de tratamento da ferida (IRION, 2005; MORAIS; OLIVEIRA; SOARES, 2008; BATES-JENSEN; NYSTUL; SCACHETTI, 2010).

Esse tratamento inclui medidas para melhorar as condições gerais do paciente e da ferida propriamente dita. Essa avaliação deve ser contínua, constante e acurada. Se não houver melhora em 2 até 4 semanas, uma reavaliação se faz necessária. A 
reavaliação deve ser feita à medida que a ferida evolui e, consequentemente, a intervenção terapêutica também poderá sofrer alterações (MORAIS; OLIVEIRA; SOARES, 2008).

O tratamento deve ser único para cada paciente, incorporando objetivos específicos para uma intervenção adequada e segura. Essa terapêutica deve ser de fácil acesso financeiro, além de permitir o monitoramento da ferida. Dependendo do tipo de tratamento, deve, ainda, fornecer isolamento térmico, permitir trocas gasosas de oxigênio, dióxido de carbono e vapor de água, ser absorvente, servir como veículo de medicamentos, melhorar as condições sistêmicas, proteger as feridas de traumas posteriores, promover uma base limpa, prevenir infecções, manter um ambiente úmido na ferida. O tipo de ferida e a forma como é tratada condicionam e definem o tipo de cicatrização (LOPES, 1999; GENOVESI; BARREIRA FILHO, 2007; SASSERON, 2010). São múltiplos os métodos e formas de tratamento de uma ferida e neste estudo abordar-se-á a LTBI, como um deles. Os laseres são uma realidade tecnológica e os de baixa potência estão sendo utilizados como coadjuvantes no tratamento de feridas, com o objetivo de auxiliar a restauração tecidual, melhorando a regeneração e a cicatrização dos tecidos. Além disso, atuam na inflamação, no edema e minimizam a dor (MELLO; MELLO; MELLO, 2001; BAPTISTA, 2003; NES; POSSO, 2005; GENOVESE; BARREIRA FILHO, 2007).

O termo laser é um acrômio da língua inglesa "light amplification by stimulated emission of radiation", ou seja, "amplificação da luz por emissão estimulada de radiação"
(CHAVANTES; TOMIMURA, 2009a; SIMÕES, 2010). O raio Laser é resultante da energia luminosa concentrada e transformada em um único raio. Existem vários tipos de laser com diferentes comprimentos de onda e frequência cujo meio ativo pode ser sólido, líquido ou gasoso, captados pela visão humana ou invisíveis, definindo a faixa espectral (LOPES, 1999; BAPTISTA, 2003; NES; POSSO, 2005; CHAVANTES; TOMIMURA, 2009a; SIMÕES, 2010).

O laser é monocromático, caracteriza-se pela capacidade de cada meio gerar um único comprimento de onda que por meio de suas biomoléculas determina a absorção da radiação incidente e, consequentemente, a interação fotobiológica e os efeitos terapêuticos específicos (MELLO; MELLO; MELLO, 2001; BAPTISTA, 2003; CHAVANTES; TOMIMURA, 2009a). Além de possuir essas peculiaridades, também é coerente e colimado, isto é, a onda senoidal apresenta coerência temporal e espacial, intensidade e direcionalidade, diferenciandoo da luz comum. Também, os "laseres" terapêuticos de baixa potência não produzem efeito térmico (BAPTISTA, 2003; CHAVANTES; TOMIMURA, 2009a).

Os equipamentos de $\mathrm{LBI}$ emitem radiação de baixa intensidade, ou seja, apresentam potência menor que 1 watt (W), sendo também denominados Soft-Laser, Laser Frio ou Laser Mole (MELLO; MELLO; MELLO, 2001; CHAVANTES; TOMIMURA, 2009b). O LBI atua modulando os processos biológicos, de tal forma que incrementa a respiração mitocondrial por sua ação na síntese de ATP elevando o metabolismo celular, ação que recebe 0 nome de "bioestimulação" (COLLS CRUAÑES, 1994; 
CHAVANTES; TOMIMURA, 2009b).

O Laser de Baixa Intensidade (LBI), também denominado de Laser de Baixa Intensidade de Potência (LBIP), Laser de Baixo Nível de Intensidade (LBNI), SoftLaser (SL), Laser Frio (LF) ou Laser Mole (LM), Intensity Laser Therapy (LILT) (BRUGNERA, PINHEIRO 1998;

CHAVANTES; TOMIMURA, 2009b), atua modulando os processos biológicos, de tal forma que incrementa a respiração mitocondrial por sua ação na síntese de ATP elevando o metabolismo celular, e a esta ação dá-se o nome de "bioestimulação" (BRUGNERA; PINHEIRO, 1998; KARU, 1999; LOPES, 1999; BAPTISTA, 2003; CARDOSO, 2003; CHAVANTES; TOMIMURA, 2009b).

Os equipamentos de LBP emitem radiação de baixa intensidade, ou seja, apresentam potência menor que 1 watt $(W)$ (CHAVANTES; TOMIMURA, 2009b. Assim, "a relação existente entre a energia total subministrada pelo emissor Laser e as áreas totais de tratamento, cuja unidade empregada é $\mathrm{J} / \mathrm{cm}^{2}$ denominada de Spatial Average Energy Fluence (SAEF)" (CHAVANTES; TOMIMURA, 2009b) e é utilizada, principalmente, em uma série de pontos distantes $2 \mathrm{~cm}$ entre si, nunca excedendo essa distância. Chavantes; Tomimura, 2009b apresentam a fórmula para se calcular os parâmetros dosimétricos da irradiação do LBP, como se segue:

$\operatorname{SAEF}\left(\mathrm{J} / \mathrm{cm}^{2}\right)=\mathrm{P}(\mathrm{W}) \cdot \mathrm{t}(\mathrm{s}) \cdot \mathrm{n} / \mathrm{A}$ $\left(\mathrm{cm}^{2}\right)$, cuja dose máxima do SAEF é de 20 $\mathrm{J} / \mathrm{cm}^{2}$.

O laser da faixa espectral vermelha age na biorregulação das organelas e o da faixa infravermelha, na membrana celular alterando sua permeabilidade e a da membrana mitocondrial resultando, como já dito, na elevação do nível celular do ATP. Portanto, o LBI tem importante ação analgésica, antiinflamatória e de restauração tecidual, sendo considerado um valioso recurso terapêutico no tratamento de feridas, por seu poder cicatrizante (COLLS CRUAÑES, 1994; BALDAN, 2005; SHIMON, 2006; SORIANO et al., 2006; CHAVANTES; TOMIMURA, 2009b).

Este estudo teve como objetivo elaborar um protocolo para a intervenção de enfermagem no tratamento de feridas utilizando LBI.

\section{METODOLOGIA}

Foi utilizada uma metodologia do tipo descritivo-exploratória, com abordagem quantitativa. O estudo foi composto de dois momentos, sendo o primeiro a realização de um levantamento da literatura nacional e internacional que abordasse a construção de protocolos para avaliação e intervenção de enfermagem em feridas, utilizando-se o LBI como terapêutica coadjuvante. Procedeu-se à leitura exploratória, catalogação e organização dos dados relacionados ao objetivo, com posterior análise descritiva, visando à fundamentação para a elaboração do protocolo proposto neste trabalho.

O segundo momento, a proposta propriamente dita do protocolo foi submetida à apreciação de 18 juízes, sendo 06 enfermeiros (03 estomaterapêutas e 03 docentes universitários), 06 físicos e 06 médicos (três dermatologistas e três clínicos, também docentes universitários) que responderam a questões abertas (sugestões e observações) e fechadas 
(concordo integralmente; concordo
parcialmente; discordo) de um questionário, que contemplava cada item do protocolo a ser avaliado. Optou-se por esse instrumento, pois, não exigindo a presença do pesquisador, permitiu aos juízes emitirem as considerações que julgassem oportunas sem qualquer tipo de interferência dos pesquisadores. Vale salientar que os físicos, independentemente, optaram por avaliar apenas a parte referente aos parâmetros da laserterapia.

$\mathrm{Na}$ parte $\mathrm{A}$ foram colocados dados de identificação do paciente, seguida da parte $B$ com dados sobre a avaliação da ferida composta de: localização e tamanho da ferida, presença de túneis, características e tipos de feridas, estágio da ferida, edema de tecido periférico, cor da pele ao redor da ferida, bordas da ferida, descolamento de borda, tipo e porcentagem do tecido da ferida, tipo de exsudato e odor, com suas respectivas caracterizações. A parte $\mathrm{C}$ refere-se ao Diagnóstico de Enfermagem, e a D refere-se às intervenções de enfermagem subdivididas em: parâmetros da Laserterapia que abordam: técnica e área de aplicação, potência de saída, diâmetro do feixe, densidade da potência por ponto irradiado, densidade de energia por ponto irradiado, Spatial Average Energy Fluence (SAEF) e tempo de irradiação e dose cumulativa total, limpeza e cobertura utilizadas.

Assim, observa-se a seguir o protocolo definitivo:

\section{Parte A - Identificação e caracterização do paciente}

A-1 Nome Endereço: Rua/Av Idade: Profissão/Ocupação:

Reg: Bairro: Sexo:

A-2 Mobilidade: Deambula Não deambula Deambula com auxílio de:

Data: Cidade:

Kg. Altura: Telefone: Outros:

A-3 Cor da Pele: branca/muito clara branca/clara moreno claro moreno mulato negro A-4 Cor dos olhos: azuis verdes castanhos claros castanhos escuros negros

A-5 Cabelos: louros ruivos castanhos claros castanhos escuros negros

A-6 Sinais Vitais: $P A: \ldots \quad X \_m m H g \quad P: \_b p m$

A-7 Alergias:

A-8 Dependência química: Cigarro ___ dia Álcool ___ dia outros:

A-9 Aspectos nutricionais:

A-10 Lesão cutânea prévia: não sim, local: 
A-11 Amputação prévia: não sim, local:

A-12 Dor: não sim, escore (VAS)*: Inicio: Término:

A-13 Patologia(s) de base:

A-14 Tratamento:

A-15 Medicamento(s) em uso:

A-16 Tempo de existência da(s) ferida(s) em meses:

A-17 Tratamento(s) anterior(es) da(s) ferida(s):

\section{Parte B - Avaliação da Ferida}

B-1- Localização e Tamanho da (s) Ferida (s):

\begin{tabular}{|c|l|l|}
\hline $\begin{array}{c}\text { Tamanho }\left(\mathrm{cm}^{2}\right) \\
\text { acetato quadriculado de } 1 \mathrm{~cm}^{2}\end{array}$ & $\begin{array}{c}\text { Profundidade } \\
(\mathrm{cm})\end{array}$ & Local \\
\hline & & $\mathrm{F}^{\star} 1:$ \\
\hline & & $\mathrm{F}^{\star} 2:$ \\
\hline & & $\mathrm{F}^{\star} 3:$ \\
\hline
\end{tabular}

${ }^{*} \mathrm{~F}=$ Ferida

B-2-Túneis: (localização e medida)

B-3- Tipo de ferida:

Cirúrgica $\left(\mathrm{F}_{\_}\right) \quad$ Traumática $\left(\mathrm{F}_{-}\right) \quad$ Cisto $\left(\mathrm{F}_{\_}\right) \quad$ Fístula $\left(\mathrm{F}_{-}\right)$Fissura $\left(\mathrm{F}_{-}\right)$

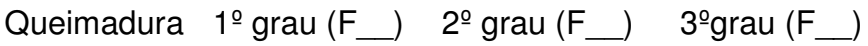

Úlceras: Úlcera por pressão $\left(F_{\_}\right)$Úlcera Venosa $\left(F_{\_}\right)$Úlcera Arterial $\left(F_{\_}\right)$

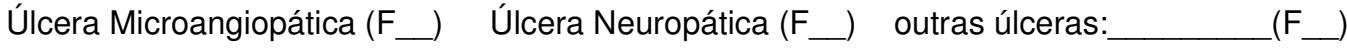
Linfedema ( $\left.\mathrm{F}_{\_}\right)$Outras:___ $\left(\mathrm{F}_{-}\right)$:

B-4- Características da ferida:

Aguda $\left(F_{\_}\right) \quad$ Crônica $\left(F_{\_}\right) \quad \operatorname{Limpa}\left(F_{\_}\right) \quad$ Contaminada $\left(F_{\_}\right) \quad$ Infectada $\left(F_{\_}\right) \quad$ Dolorosa( $\left.F_{\_}\right)$

B-5- Tipo de cicatrização:

Primeira Intenção ( $\left.F_{\_}\right) \quad$ Segunda Intenção $\left(F_{\_}\right) \quad$ Terceira Intenção $\left(F_{-}\right)$

\section{B-6- Estágio da Ferida:}

Eritema persistente da pele íntegra; $\left(\mathrm{F}_{-}\right)$

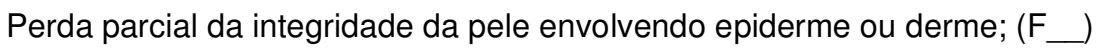

Perda total da integridade da pele envolvendo lesão ou necrose do tecido subcutâneo; ( $\mathrm{F}_{\text {_ }}$ )

Perda total da integridade da pele com destruição externa, necrose dos tecidos ou lesão de músculos, ossos ou estrutura de suporte. $\left(\mathrm{F}_{-}\right.$)

OBS: 
B7- Tipo de tecido no leito da ferida e porcentagem:

\begin{tabular}{|l|l|l|l|l|}
\hline \multicolumn{1}{|c|}{ Tipo de Tecido } & \multicolumn{3}{c|}{ Porcentagem } \\
\hline Epitelial & F1 & F2 & F3 & F4 \\
\hline Granulação & & & & \\
\hline Fibrina & & & & \\
\hline Necrótico que começa a afrouxar & & & & \\
\hline Necrótica preta & & & & \\
\hline Necrótica seca & & & & \\
\hline
\end{tabular}

B-8- Exsudato:

\begin{tabular}{|lcccc|lcccc|}
\hline \multicolumn{4}{|c}{ Quantidade/volume } & \multicolumn{9}{|c|}{ Tipo } \\
\hline Nenhum & F1 & F2 & F3 & F4 & Nenhum & F1 & F2 & F3 & F4 \\
\hline Escasso & F1 & F2 & F3 & F4 & Seroso & F1 & F2 & F3 & F4 \\
\hline Pouco (até 5 gazes) & F1 & F2 & F3 & F4 & Sanguinolento & F1 & F2 & F3 & F4 \\
\hline Moderado (até 10 gazes) & F1 & F2 & F3 & F4 & Serosanguinolen & F1 & F2 & F3 & F4 \\
\hline Acentuado (> 10 gazes) & F1 & F2 & F3 & F4 & Serofibrinoso & F1 & F2 & F3 & F4 \\
\hline & & & & & Seropurulento & F1 & F2 & F3 & F4 \\
\hline & & & & & Purulento & F1 & F2 & F3 & F4 \\
\hline
\end{tabular}

B-9-Odor: ausente $\left(\mathrm{F}_{-}\right)$discreto $\left(\mathrm{F}_{\_}\right)$acentuado $\left(\mathrm{F}_{-}\right)$Características:

\section{B-10- Borda:}

aderida $\left(\mathrm{F}_{\_}\right) \quad \operatorname{descolada}\left(\mathrm{F}_{\_}\right) \mathrm{cm} \_\operatorname{regular}\left(\mathrm{F}_{-}\right) \quad \operatorname{irregular}\left(\mathrm{F}_{-}\right)$

hiperqueratótica $\left(\mathrm{F}_{\_}\right) \quad$ macerada $\left(\mathrm{F}_{\_}\right) \quad \operatorname{circular}\left(\mathrm{F}_{\_}\right) \quad$ plana $\left(\mathrm{F}_{-}\right)$

nivelada com o leito da ferida ( $\left.F_{[}\right)$não nivelada com o leito da ferida ( $F_{-}$)

enrolada para fora ( $\left.\mathrm{F}_{-}\right)$enrolada para dentro ( $\mathrm{F}_{-}$)

B-11- Região Periferida - Presença de:

Dermatoesclerose $\left(\mathrm{F}_{\_}\right) \quad$ Hiperqueratose $\left(\mathrm{F}_{\_}\right)$Maceração $\left(\mathrm{F}_{\_}\right)$Fissuras $\left(\mathrm{F}_{\_}\right)$

Hiperemia $\left(\mathrm{F}_{\_}\right) \quad$ Descamação $\left(\mathrm{F}_{\_}\right)$Ressecamento ( $\left.\mathrm{F}_{-}\right)$

Ressecamento c/ descamação $\left(\mathrm{F}_{-}\right) \quad$ Eczema $\left(\mathrm{F}_{-}\right)$Prurido $\left(\mathrm{F}_{-}\right)$

B-12- Cor da pele (periferida):

Rosa ou normal para o grupo etnico; $\left(\mathrm{F}_{\_}\right)$Branca ou cinza pálida ou hipopigmentada $\left(\mathrm{F}_{\_}\right)$ Vermelho brilhante ( $F_{\_}$) Vermelha escura ou púrpura e/ou sem empalidecimento ( $F_{-}$) preta ou hiperpigmentada/dermatite ocre $\left(\mathrm{F}_{\ldots}\right)$

B-13- Edema:

ausente $\left(\mathrm{F}_{-}\right) \quad+/ 4\left(\mathrm{~F}_{-}\right) \quad++/ 4\left(\mathrm{~F}_{-}\right) \quad+++/ 4\left(\mathrm{~F}_{-}\right) \quad++++/ 4\left(\mathrm{~F}_{-}\right)$

Parte C: Diagnóstico(s) de Enfermagem

C-1 


\section{Parte D: Intervenções de enfermagem/Tratamento:}

D-1- Parâmetros para irradiação na Ferida-

Equipamento: LBI (Laser Baixa Intensidade) marca:

Comprimento de onda:

DE irradiada: $P$ (Potência):

W Diâmetro do feixe:

$\mathrm{J} / \mathrm{cm}^{2}$ SAEF:

$D E$ (densidade de energia ou fluência) por ponto:
Aplicação no:

OBS:

D-2 Barreira de proteção: não filme de PVC

curativo de filme adesivo transparente (poliuretano) outros:

D-3 Forma de aplicação: scanner ponteira ___ outro:

Modo: pontual varredura

Técnica: com contato sem contato ambos:

contínuo (CW)

D-4 Área e forma de aplicação:

margem leito ambos outro(s) locais:

OBS:

Área total de aplicação: __ $\mathrm{cm}^{2}$, $\mathrm{n}$ ㅇ de pontos: no leito

Tempo de aplicação por ponto: no leito na margem na margem outro(s) locais

Periodicidade: 1x/semana 2x/semana com intervalo de

Dia(s) da semana: segunda terça quarta quinta sexta sábado domingo

D-5 Produtos utilizados:

Limpeza e cobertura primária:

Cobertura secundária:

É conveniente ressaltar que foram respeitadas todas as determinações éticas de pesquisa envolvidas neste trabalho seguindo o disposto na Resolução no. 196 de 10 de outubro de 1996 do Conselho Nacional de Saúde.

\section{RESULTADOS E DISCUSSÃO}

A apreciação ou ajuizamento é um cuidado que o pesquisador deve ter ao criar um instrumento/protocolo. Neste trabalho, a submissão dessa proposta a juízes expertos no assunto, antes de validá-lo na prática clínica, aqui chamada de ajuizamento, foi um cuidado adotado no intuito de se assegurar sobre a compreensão, pertinência, confiabilidade, entre outras características, da abrangência, objetividade e clareza do conteúdo. Procurou, ainda, garantir a imparcialidade dos autores e/ou ainda, minimamente, cometer a deselegância de impor um protocolo sem um parecer douto e imparcial de especialistas. Assim, o corpo de juízes foi composto por profissionais expertos no assunto e em suas especialidades que aceitaram participar voluntariamente.

Para os juizes, o instrumento/protocolo mostrou excelente abrangência do tema, pois todos consideraram como importantes todos os itens do instrumento/protocolo e concordaram por englobar dados relevantes para a avaliação e tratamento efetivo da 
ferida. Este resultado encontra ressonância com 0 que a literatura define como propriedades de um bom instrumento/protocolo, isto é, sua capacidade de mensurar de forma apropriada o que se propôs e apresentar conteúdo abrangente do tema permitindo a reprodutibilidade, ou seja, chegar aos mesmos resultados quando aplicado em outra situação sob as mesmas circunstâncias (SELVA et al., 1999; SANTOS et al., 2005).

Além disso, a confiabilidade e validade são determinadas pela concordância completa ou maior coerência nas respostas interobservadores (SELVA et al., 1999; LOBIONDO-WOOD; HABER, 2001; SANTOS et al., 2005), representando o maior número de concordâncias obtidas nas respostas do estudo com o resultado real ou "padrão ouro". Neste estudo, a confiabilidade e a validade puderam ser verificadas pelas congruências entre as respostas dos pares de juízes, que de forma unânime consideraram a proposta abrangente, necessária e importante para a avaliação e tratamento da ferida.

Para os $06(33,3 \%)$ físicos que se propuseram a avaliar somente os itens referentes aos parâmetros da laserterapia, os julgaram como coerentes e sugeriram algumas complementações que não modificaram a essência do instrumento/protocolo, tais como: a relação existente entre a energia total ministrada pelo laser e as áreas totais de tratamento, ou seja, o SAEF e a distância entre os pontos de aplicação e, ainda, salientaram a importância e necessidade deste instrumento/ protocolo, que além de sistematizar a aplicação, ainda oferece dados para documentá-la.

Ainda, 02 (11,1\%) juízes, sendo 01 médico (docente/dermatologista) e 01 enfermeiro (docente), sugeriram alterar a sequência de algumas questões, porém, sem modificar seu conteúdo. Estas sugestões foram totalmente integradas à proposta para na próxima etapa, a da aplicação do protocolo instrumento, facilitar sua utilização e compreensão. Vale salientar que essa etapa está em fase de execução, após observar todos os cuidados éticos e institucionais que tal aplicação exige.

\section{CONCLUSÃO}

Os resultados obtidos permitem inferir que a proposta do instrumento/protocolo é importante e necessária segundo a avaliação dos 18 juízes para a terapêutica com LBI em feridas, para detectar possíveis deficiências e propor medidas corretivas. Acredita-se que esse processo de ajuizar um protocolo, torna consistente, confiável e qualificado o desempenho de determinado procedimento ou de uma futura validação. Esse processo exige, também, comprometimento, atualização e capacitação da equipe envolvida, ao mesmo tempo em que sistematiza e padroniza a assistência à saúde.

\section{REFERÊNCIAS}

AZULAY, R. D.; AZULAY, D. R. Dermatologia. 4. ed. Rio de Janeiro: Guanabara Koogan; 2006. 664 p.

BAPTISTA, I. M. C. Análise do efeito do laser de baixa intensidade na prevenção de deiscência incisional em cirurgia cardíaca. 
$2003 . \quad$ Dissertação (Mestrado em
Bioengenharia) Instituto de Pesquisa e Desenvolvimento. Universidade do Vale do Paraíba, São José dos Campos, 2003.

BALDAN, C. Ação do laser vermelho de baixa potência na viabilidade de retalhos cutâneos randômicos em ratos. 2005. Dissertação (Mestrado em CiênciasFisiopatologia Experimental) Universidade de São Paulo, São Paulo, 2005. Disponível em:

$<$ http://www.teses.usp.br/teses/disponiveis/5/ 5160/tde-05092005-112310/pt-br.php>.

BATES-JENSEN，B. M.; NYSTUL, S. N.; SCACHETTI, G. G. Prevenção da úlcera por pressão por parte do cuidador domiciliar. In: MALAGUTTI, W.; KAKIHARA, C. T. Curativo, estomias e dermatologia: uma abordagem multiprofissional. São Paulo: Martinari; 2010. p. 247-281.

BRUGNERA JR., A.; PINHEIRO, A. L. B Lasers na odontologia moderna. São Paulo: Pancast, 1998. pp. 19-78, 101-20, 223-31.

CARDOSO, C. A. C. Análise histomorfométrica do reparo tecidual após laserterapia e aplicações de adesivo, 2003. 87 p Dissertação (mestrado em Engenharia Biomédica) Instituto de Pesquisa e Desenvolvimento, Universidade do Vale do Paraíba, São José dos Campos, 2003.

CHAVANTES, M.C; TOMIMURA, S Fundamentos do Laser. In: CHAVANTES, M.C. (org.). Laser em bio-medicina: princípios e prática. São Paulo: Atheneu; 2009a p. 15-27.

CHAVANTES, M. C.; TOMIMURA, S. Classificação dos Laseres. In: CHAVANTES, M. C. (org.). Laser em biomedicina: princípios e prática. São Paulo:
Atheneu; 2009b p. 41-67.

COLLS CRUAÑES, J. La terapia laser hoy. Barcelona: Centro de Documentación Laser de meditec; 1994. p. 52-59.

DAVENPORT, J. Anatomia e fisiologia do sistema tegumentar In: MORTON, P. G. et al. Cuidados críticos de enfermagem: uma abordagem holística. 8. ed. Rio de Janeiro: Guanabara Koogan; 2007. p. 1207-1211.

GENOVESE, W. J.; BARREIRA FILHO, J. L. Efeitos terapêuticos dos laseres de baixa intensidade. In: GENOVESE, W.J. Laser de baixa intensidade: Aplicações terapêuticas em odontologia. São Paulo: Santos; 2007. p.39-46.

IRION, G. Feridas: novas abordagens, manejo clínico e Atlas em cores. Trad. de João Clemente Dantas do Rego Barros. Rio de Janeiro: Guanabara Koogan; 2005. p. 338-359.

KANITAKIS, J. Anatomy, histology and immunohistochemistry of normal human skin. European J. Dermatol., v. 12, n.4, p. 390-401, 2002.

KARU, T. Primary and secondary mechanisms of action of visible to near-IR radiation on cells. Journal Photochemistry and Photobiology B, v. 49, p. 1-17, 1999.

LOBIONDO-WOOD, G.; HABER, J. . Pesquisa em enfermagem: métodos, avaliação crítica e utilização. 4. ed. Rio de Janeiro: Guanabara-Koogan; 2001. p.186199.

LOPES, L. A. Análise in vitro da proliferação celular de fibroblastos de gengiva humana tratados com laser de baixa potência. 1999. Dissertação (Mestrado em Engenharia Biomédica) Instituto de Pesquisa e 
Desenvolvimento. Universidade do Vale do Paraíba, São José dos Campos, 1999.

MEIRELES, I. B. et al. Interdisciplinaridade no tratamento de feridas. In: SILVA, R. C. L.; FIGUEIREDO, N. M. A.; MEIRELES, I. B. Feridas: fundamentos e atualizações em enfermagem. 2. ed. São Caetano do Sul: Yendis; 2007. p. 33-54.

MELLO, J. B; MELLO, G. P. S; MELLO, L. S. Laser de baixa potência. In: MELLO, J.B; MELLO, G. P. S. Laser em Odontologia. São Paulo: Santos; 2001. p. 71-85.

MORAIS, G. F. C.; OLIVEIRA, S. H. S.; SOARES, M. J. G. O. Avaliação de feridas pelos enfermeiros de instituições hospitalares da rede pública. Texto Cont. Enf., v. 17, n.1, p.98-105 jan/mar. 2008.

NES, A. G.; POSSO, M. B. S. Patients with moderate chemotherapy-induced mucositis: pain therapy using low intensity lasers. International Nursing Review, v. 52, p. 6872, 2005.

SAMPAIO, S. A. P.; RIVITTI, E. A. Dermatologia. 3. ed. São Paulo: Artes Médicas, 2007.

SANTOS, V. L. C. G. et al. Adaptação transcultural do pressure ulcer scale for healing (PUSH) para a língua portuguesa. Rev. Latino-am. Enfermagem., v. 13, n.3, p. 305-313, maio-jun. 2005.

SASSERON, M. G. M. Atualizações em curativos oclusivos e semioclusivos. In: MALAGUTTI, W; KAKIHARA, C.T. Curativo, estomias e dermatologia: uma abordagem multiprofissional. São Paulo: Martinari; 2010. p. 129-147.

SELVA, T. S. et al. Validez del protocolo de adecuación de urgencias hospitalarias. Rev. Esp. Salud Publica, v. 73, n. 4, p. 461-475, jul./ago.1999.

SHIMON, R. Photoengineering of neural tissue repair processes in peripheral nerves and the spinal cord: research development with clinical applications. Photomedicine and Laser Surgery, v. 24, n. 2, p. 151-157, Apr. 2006.

SIMÕES, N. D. P. Laser no tratamento de feridas, estomias e Dermatologia. In: MALAGUTTI, W.; KAKIHARA, C. T. Curativo, estomias e dermatologia: uma abordagem multiprofissional. São Paulo: Martinari; 2010. p. 355-369.

SORIANO, F. et al. Photobiomodulation of pain and inflammation in microcrystalline arthropathies: experimental and clinical results. Photomedicine and Laser Surgery, v. 24, n. 2, p. 140-150, Apri. 2006. 